\title{
Ultrathin and nanostructured ZnO-based films for fluorescence biosensing applications
}

\author{
Cristina Satriano $^{\mathrm{a}, *}$, Maria Elena Fragalà ${ }^{\mathrm{a}}$, Yana Aleeva ${ }^{\mathrm{b}}$ \\ ${ }^{a}$ Dipartimento di Scienze Chimiche, Università degli Studi di Catania and INSTM, viale Andrea Doria n. 6, 95125 Catania, Italy

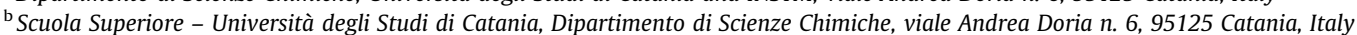

\section{A R T I C L E I N F O}

\section{Article history:}

Received 12 June 2011

Accepted 9 September 2011

Available online 17 September 2011

\section{Keywords:}

$\mathrm{ZnO}$ thin film

MOCVD-colloidal lithography

Biosensing

Protein adsorption

Fluorescence recovery after photobleaching

\begin{abstract}
A B S T R A C T
The fluorescence-based sensing capability of ultrathin $\mathrm{ZnO}-\mathrm{SiO}_{2}$ nanoplatforms, deposited by an integrated approach of colloidal lithography and metal organic chemical vapor deposition, has been investigated upon adsorption of fluorescein-labeled albumin, used as model analyte biomolecule. The protein immobilization process after spontaneous adsorption/desorption significantly enhances the green emission of the different ZnO-based films, as evidenced by scanning confocal microscopy, corresponding to a comparable protein coverage detected by X-ray photoelectron spectroscopy. Moreover, experiments of fluorescence recovery after photobleaching evidence that the protein lateral diffusion at the biointerface is affected by the chemical and/or topographical patterning of hybrid $\mathrm{ZnO}^{-\mathrm{SiO}_{2}}$ surfaces. The used approach is very promising for biomolecular detection applications of these $\mathrm{ZnO}-\mathrm{SiO}_{2}$ nanoplatforms, by simple sizing of the $2 \mathrm{D}$ vs. 3D patterning design, which in turn is accomplished by the fine tuning of the integrated colloidal lithography-chemical vapor deposition processes.
\end{abstract}

(c) 2011 Elsevier Inc. All rights reserved.

\section{Introduction}

Development of advanced substrates for biomolecular sensing is critically related to multitasking capability, sensitivity and specificity aspects. An emergent field of research for various applications in biomolecular detection is the innovative assembly of zinc oxide nanostructures [1,2]. Indeed, zinc oxide ( $\mathrm{ZnO})$ is an extremely versatile material even at the nanoscale, due to processing through many synthetic routes [3], easy integration into periodically patterned nanoplatforms [4-6], desirable optical properties [7] and stability in typical biomolecular detection environments [8]. Moreover, nanostructured $\mathrm{ZnO}$ materials possess high surface area and good biocompatibility and biodegradability [9] that make them very advantageous as platforms to detect the immobilization of glucose [10], cholesterol [11], DNA [5,12] and several other biomolecules [13-16]. In particular, examples of the use of nanoscale $\mathrm{ZnO}$ in the enhanced fluorescence detection of protein interactions have shown that $\mathrm{ZnO}$ can act as an excellent signal-intensifying substrate for a wide range of biomolecules $[1,17,18]$. Recently, the ultra-sensitivity of zinc oxide nanorod arrays in conjunction with a FITC-labeled affinity peptide has been successfully demonstrated for biosensing applications [19].

As to the fabrication of nanostructured platforms, in recent years, the synthetic strategy of combining colloidal lithography

\footnotetext{
* Corresponding author. Fax: +39 095580138.

E-mail address: csatriano@unict.it (C. Satriano).
}

(CL) with several deposition techniques, including metal-organic chemical vapor deposition (MOCVD) [18,21], self-assembled monolayers [22], plasma processes [23,24], drop casting [25] and metal sputter/coating processes [26,27], has been proven effective to fabricate chemical/topographical patterns for driving protein adsorption and cell adhesion.

In previous works, we demonstrated the successful process integration of MOCVD processes, at unusual mild conditions (i.e., low temperature/short deposition time), with colloidal lithography to assemble $\mathrm{ZnO}$ ultrathin films into periodic arrays of micro/ nanopores [4,20], exhibiting sensitive and specific detection of surface immobilized proteins [18]. To proceed with such investigations, we focus herein on the chemical, topographical and optical characterization of these ultrathin $\mathrm{ZnO}$ films and hybrid $\mathrm{ZnO}-$ $\mathrm{SiO}_{2}$ micropore arrays. A multitechnique approach involving Xray photoelectron spectroscopy (XPS), scanning electron microscopy (SEM) and laser scanning confocal microscopy (LSM) has been used.

Moreover, the hybrid biointerface with fluorescein-labeled albumin, used as model analyte biomolecule, is investigated by means of fluorescence recovery after photobleaching (FRAP) experiments. The results demonstrate that such ultrathin films have great potential as innovative fluorescence-sensing substrates, offering the possibility of sizing the $2 \mathrm{D}$ vs. 3D design of the $\mathrm{ZnO}-\mathrm{SiO}_{2}$ array (through the fine tuning of CL and MOCVD conditions), which, in turn, affects the individual addressability of the biomolecular detection. 


\section{Materials and methods}

\subsection{Metal-organic chemical vapor deposition (MOCVD) and integrated MOCVD-colloidal lithography}

$\mathrm{ZnO}$ deposition was performed in a horizontal hot-wall MOCVD reactor at a pressure of about 5 Torr, by using $\mathrm{Zn}(\mathrm{tta})_{2}$ tmeda precursor, $\mathrm{Ar}$ (250 sccm, carrier gas) and $\mathrm{O}_{2}(250 \mathrm{sccm}$, reaction gas) $[28,29]$. The substrates used for the deposition were (i) monopolished (100) silicon (University Wafer), for XPS and SEM analyses, and (ii) glass coverslip (Biopthecs), for LSM measurements. Three sets of samples were produced at the following temperature/time deposition conditions, namely $300^{\circ} \mathrm{C} / 40 \mathrm{~m}, 400{ }^{\circ} \mathrm{C} / 5 \mathrm{~min}$ and $400{ }^{\circ} \mathrm{C} / 60$ min (thereafter named, respectively, ZnO-1, ZnO-2 and $\mathrm{ZnO}-3$ ) to end up with 12 different samples.

A parallel set of samples was prepared by integrating the MOCVD $\left(400^{\circ} \mathrm{C} / 5 \mathrm{~min}\right)$ with the $\mathrm{CL}$ technique ( $\mathrm{ZnO}-2 \mathrm{NP}$ samples). Briefly, the substrates were masked by a 2D close-packed monolayer of polystyrene colloids of 1 micrometer of diameter (Sigma), self-assembled by dewetting ( $1 \mathrm{wt} . \%$ in aqueous solution), MOCVD was performed, and colloids were removed $[4,20]$.

\subsection{Protein immobilization at the $\mathrm{ZnO}-\mathrm{SiO}_{2}$ surfaces}

Fluorescein isothiocyanate-labeled albumin (FITC-albumin) was purchased as powder (Sigma) and used as received after dissolving in $0.01 \mathrm{M}$ phosphate buffer saline solution containing $0.003 \mathrm{M} \mathrm{KCl}$ and $0.14 \mathrm{M} \mathrm{NaCl}$ (PBS, pH 7.4 at $25^{\circ} \mathrm{C}$, Sigma).

As indicated by the supplier, the chromophore is coupled to the protein through the $\varepsilon$-amino group of lysines of the albumin, and the labeling density corresponds to a degree of substitution of 712 moles of FITC per mole of albumin.

The protein was immobilized on the $\mathrm{ZnO}$-based films by spontaneous adsorption from $100 \mu \mathrm{g} / \mathrm{mL}$ solution in PBS (40-min incubation time), followed by gentle rinsing with PBS and drying by dewetting in controlled laboratory atmosphere. The fluorescence signal-enhancing capability of $\mathrm{ZnO}$-based films was assessed in situ by using an experimental configuration consisting of the substrates in contact with the protein solution ( $50 \mu \mathrm{L}$ drop) during an established incubation time ( $40 \mathrm{~min}$ ), thus rinsing with PBS to remove unbound protein molecules.

\subsection{Physicochemical characterization of the protein-ZnO biointerface}

X-ray photoelectron spectroscopy (XPS) analyses were performed by using a PHI ESCA/SAM 5600 multitechnique spectrometer. Experiments were carried out with the standard $\mathrm{Al} \mathrm{K \alpha}$ radiation source ( $h v=1486.6 \mathrm{eV}$ ) at a base pressure of $2 \times 10^{-9}$ Torr. XPS spectra were collected at a photoelectron take-off angle of $45^{\circ}$, which, according to the effective attenuation length values, respectively, of $0.74 \mathrm{~nm}$, for photoelectron from $\mathrm{Zn} 2 \mathrm{p}$ traveling in $\mathrm{ZnO}$ [30], and of $3.13 \mathrm{~nm}$, for Si 2p photoelectrons in an organic layer [31], roughly corresponds to an actual sampling depth in the range from about $1.6 \mathrm{~nm}$ (bulk $\mathrm{ZnO}$ ) up to about $6.4 \mathrm{~nm}$ (bulk $\mathrm{SiO}_{2}$ ). Both survey and narrow region scans were recorded, namely $\mathrm{Zn} 2 \mathrm{p}, \mathrm{C} 1 \mathrm{~s}$, Si 2p, O 1s and N 1s peaks, at pass energy and incremental step size of $150 \mathrm{eV} / 1 \mathrm{eV}$ for survey and $11.85 \mathrm{eV} / 0.05 \mathrm{eV}$ for the narrow scans, respectively.

The XPS signals were analyzed with a peak synthesis program based on a non-linear background and experimental bounds fitting by Gaussian components. The atomic elemental compositions were evaluated using sensitivity factors provided by the F V5.4A software. All binding energies were referenced to $C 1 \mathrm{~s}$ neutral carbon peak at $285 \mathrm{eV}$.
Morphologies of the $\mathrm{ZnO}$ films were investigated using a LEO Supra 55VP field emission scanning electron microscope (FEGSEM).

\subsection{Fluorescence microscopy-fluorescence recovery after photobleaching (FRAP)}

Observations were carried out by using an Olympus FV1000 confocal laser scanning microscope (LSM) equipped with a diode Ar laser, oil immersion objective $(60 \times 03$ PLAPO) and spectral filtering system. Excitation wavelength was set at $488 \mathrm{~nm}$, and emitted light was detected at $519 \mathrm{~nm}$ (micrographs) or in the spectral range $490-620 \mathrm{~nm}$.

The detector gain was fixed at a constant value, and images were taken for all of the samples, at random locations throughout the area of protein adsorption as well as at the borderline between protein-exposed and bare surfaces, in order to compare quantitatively the fluorescence due to the antigen coverage and that to due background noise. The latter was analyzed to have control areas; therefore, the only difference between the control and target samples is the presence of protein.

The average fluorescence intensity was calculated by taking the mean pixel luminance intensity for all pixels within a $5-\mu \mathrm{m}^{2}$ area over at least 10 separate measurements. Intensity data were analyzed by one-way analysis of variance (ANOVA) with a TukeyKramer multiple comparisons test. For the fluorescence recovery after photobleaching (FRAP) investigations, the data were normalized to the initial (pre-photobleach) value, which enables the percentage of photobleaching and the percentage fluorescence recovery within the laser region to be determined. For each sample, the emission recorded from the bleached spots was compared with that coming from contiguous non-bleached areas. Bare glass substrates were used for comparison. The samples were bleached for 1 min using high intensity (95\% power) on the laser, immediately after a micrograph was taken every $1 \mathrm{~min}$ up to $10 \mathrm{~min}$. By translating the sample stage, an average of 15 spots per substrate were photobleached in a given experiment.

\section{Results and discussion}

\subsection{Physicochemical characterization of ultrathin $\mathrm{ZnO}$-based films}

SEM analyses were used for monitoring the morphological differences between the surfaces resulting from deposition at the different MOCVD time/temperature conditions on the silicon substrates (Fig. 1).

Fig. 1a shows that $\mathrm{ZnO}-1$ sample (i.e., the film deposited at $300{ }^{\circ} \mathrm{C} / 40 \mathrm{~min}$ ) is characterized by a granular structure with a bimodal ZnO grain size distribution, showing a predominance of small grains (about $15 \mathrm{~nm}$ of average dimension) and few large grains (about $50 \mathrm{~nm}$ of average diameter) randomly distributed over the surface. As to the $\mathrm{ZnO}-2$ sample (i.e., $400^{\circ} \mathrm{C} / 5 \mathrm{~min}$ ), a smoother morphology is well evident (Fig. 1b) with about 50-nmlarge grains clearly visible on the substrate. Finally, the $\mathrm{ZnO}-3$ sample (i.e., $400{ }^{\circ} \mathrm{C} / 60 \mathrm{~min}$, Fig. 1c), used as control thick film, shows a homogeneous granular morphology characterized by fairly welldefined round grains having average dimensions of about 10$15 \mathrm{~nm}$ [30]. The morphological results provide confidence about two different $\mathrm{ZnO}$ deposition mechanisms, depending on the specific deposition temperature used. In particular, for the films deposited at the low temperature $\left(300{ }^{\circ} \mathrm{C}\right)$, the ad atoms' mobility at the substrate surface during the MOCVD process is likely to be rather limited, thus resulting in a prevalence of an island-like $\mathrm{ZnO}$ layer formation (3D growth mode). On the other hand, upon increasing the deposition temperature $\left(400^{\circ} \mathrm{C}\right)$, the formation of a continuous 


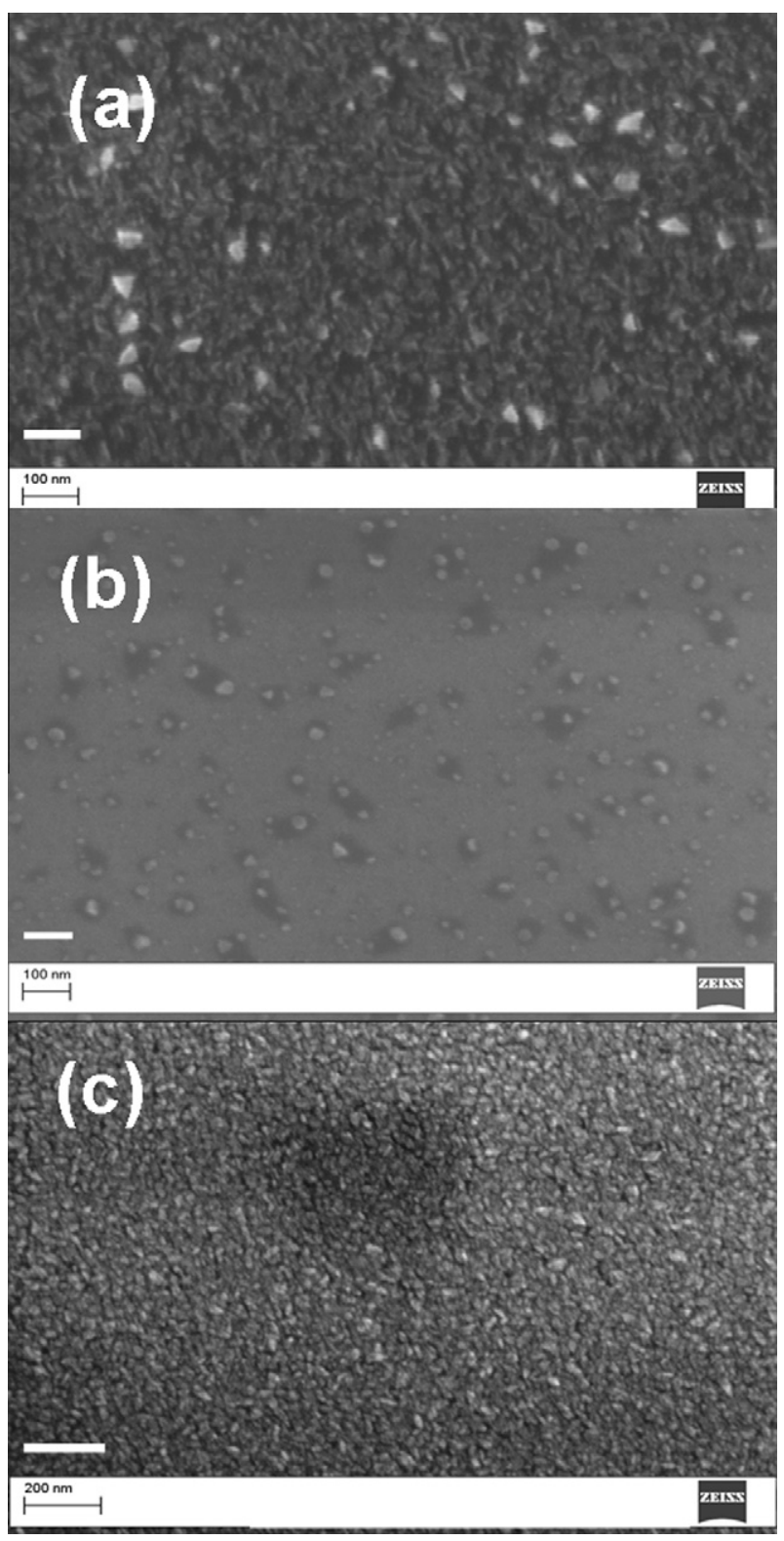

Fig. 1. SEM images of the ZnO-based films: (a) ZnO-1, (b) ZnO-2, (c) ZnO-3.

layer is favoured, both kinetically and thermodynamically, due to coalescence of the isolated $\mathrm{ZnO}$ grains (growth mode transition from $3 \mathrm{D}$ to $2 \mathrm{D}$ ) and the final $\mathrm{ZnO}$ surface morphology becomes smoother.

The surface chemical composition of the whole-set $\mathrm{ZnO}$ samples as well as the control silicon substrate is given in Table 1.

\section{Table 1}

XPS quantitative analysis in terms of average atomic composition (at.\%) and characteristic ratios for the $\mathrm{ZnO}$ films. ${ }^{\mathrm{a}}$

\begin{tabular}{lllllll}
\hline Sample & Si & O & C & Zn & Zn/Si & C/Zn \\
\hline Si & 53 & 14 & 33 & - & - & - \\
ZnO-1 & 0.1 & 51 & 35 & 14 & 140.0 & 2.5 \\
ZnO-2 & 11 & 44 & 25 & 20 & 1.8 & 1.3 \\
ZnO-3 & 0.1 & 45 & 26 & 29 & 290.0 & 0.9
\end{tabular}

a The relative standard deviation (RDS) calculated over three separate analyses of different samples results lower or comparable to the experimental XPS error, i.e., $\pm 2 \%$ ).
It is interesting to note that the detected silicon signal, characteristic of the substrate, is negligible (below the significance of the experimental error at the used conditions, i.e., $2 \%$ of atomic composition) for both $\mathrm{ZnO}-1$ and $\mathrm{ZnO}-3$ samples, but not for the $\mathrm{ZnO}-2$, where a silicon signal attenuation of about $80 \%$ compared to the bare substrate is measured. This finding indicates that the complete coverage of the underlying silicon, in terms of the present XPS sampling depth (see Section 2.3), is obtained for $\mathrm{ZnO}-1$ and the thick $\mathrm{ZnO}-3$ samples. As a consequence of the mild $\mathrm{ZnO}-1$ deposition conditions, a relatively low zinc content and a corresponding high $\mathrm{C} / \mathrm{Zn}$ ratio point to significant carbonaceous residuals at the surface, which are mostly due to unreacted precursor as well as unavoidable surface hydrocarbon contamination.

In the case of $\mathrm{ZnO}-2$ sample, notwithstanding the significant silicon signal detected, both the $\mathrm{C} / \mathrm{Zn}$ atomic ratio and the zinc atomic content point to a surface chemical composition comparable to that of $\mathrm{ZnO}-3$ sample (i.e., temperature-driven efficiency to control the precursor decomposition), but with a lower film thickness and uniformity (i.e., insufficient deposition time to attain the complete coverage).

To summarize, XPS analysis evidences that the newly prepared $\mathrm{ZnO}-1$ and $\mathrm{ZnO}-2$ films consist of heterogeneous ultrathin (less than $10 \mathrm{~nm}$ ) ZnO-based films having different chemical compositions with respect to the presence of carbon-related species, as well as different surface coverage.

\subsection{Protein interaction with the ultrathin $\mathrm{ZnO}$-based films}

Based on previously described studies, albumin is expected to irreversibly bind on ZnO surfaces by spontaneous adsorption driven by electrostatic interactions, at the physiological $\mathrm{pH}$ of 7.4 [21].

Aim of this work is to investigate the interface between such films and albumin, used as model analyte biomolecule, in terms of (i) the change in emission properties of $\mathrm{ZnO}$; (ii) the biomolecule lateral mobility in the adlayer; and (iii) the protein surface coverage and its average orientation. XPS and confocal microscopy with the application of the FRAP technique were used to this purpose.

The XPS quantitative analysis of the samples exposed to FITCalbumin solution (Table 2) indicates that, after the spontaneous protein adsorption followed by rinsing out of the weakly bound molecules, a certain amount of irreversibly immobilized protein is detected at the surfaces of all the ultrathin $\mathrm{ZnO}$-based films as well as the two reference controls, namely bare silicon (i.e., about 10-nm-thick native silicon oxide on silicon) and $\mathrm{ZnO}-3$ (about 50 nm-thick $\mathrm{ZnO}$ ).

The comparison between the protein-characteristic nitrogen signals detected at the surfaces of all the above-mentioned samples (about 5-6\%) and the value of about $14 \%$ found for an ideally thick FITC-albumin adlayer (at least for the sampled depth of about $1.4 \mathrm{~nm}$ at the used experimental conditions) indicates a protein coverage roughly corresponding to the half of a monolayer [21]. However, it should be noted that the analytical quantification of protein coverage on the investigated substrates is affected by the

Table 2

XPS quantitative analysis in terms of average atomic composition (at.\%) for the different $\mathrm{ZnO}$ films after albumin absorption. ${ }^{\mathrm{a}}$

\begin{tabular}{llllll}
\hline Sample & Si & O & C & Zn & N \\
\hline Si + FITC-albumin & 14 & 37 & 41 & - & 6 \\
ZnO-1 + FITC-albumin & 6 & 29 & 58 & 2 & 5 \\
ZnO-2 + FITC-albumin & 10 & 40 & 37 & 7 & 6 \\
ZnO-3 + FITC-albumin & - & 48 & 38 & 8 & 6 \\
FITC-albumin & - & 58 & 28 & - & 14 \\
\hline
\end{tabular}

a The relative standard deviation (RDS) calculated over three separate analyses of different samples results lower or comparable to the experimental XPS error, i.e., $\pm 2 \%$ ). 
expected partial surface dissolution of $\mathrm{ZnO}$, due to the large concentration of unsaturated bonds, $-\mathrm{OH}$ groups and polar moieties that can readily interact with the protein molecules, thus promoting a prompt biodegradability. In fact, the biodegradation of $\mathrm{ZnO}$ in aqueous media and biofluids is a well-known process with important implications for biomedical applications [9]. $\mathrm{ZnO}$ is poorly soluble in water, but it can slowly dissolve in both acidic and strong basic conditions [32]. However, presence of biological components such as proteins and amino acids can also enhance the oxide dissolution through the complexation of the $\mathrm{Zn}^{2+}$ free ions released from the material surface [33-35].

Accordingly, we detect a silicon content of about $6 \%$ at the ZnO-1 surface after the protein adsorption (Table 2), while no significant silicon signal had been detected for the bare $\mathrm{ZnO}-1$ film (Table 1). On the contrary, the silicon content detected at $\mathrm{ZnO}-2$ surfaces does not change after exposure to the protein solution and similarly, no silicon is detected onto the albumin-immobilized ZnO-3 samples. These findings can be explained by considering the different surface termination and composition of the low-temperature deposited films (i.e., $\mathrm{ZnO}-1$ ) compared with those deposited at the higher temperature (i.e., $\mathrm{ZnO}-2$ and $\mathrm{ZnO}-3$ ). In particular, the observed biodegradation of the $\mathrm{ZnO}-1$ surfaces is likely the result of stronger protein-surface interaction at the biointerface than that in the case of $\mathrm{ZnO}-2$ and $\mathrm{ZnO}-3$ samples.

The detailed analysis of carbon and oxygen photoelectron peaks before and after the interaction with the protein further supports these data interpretation and adds significant hints about the average protein orientation at the $\mathrm{ZnO}$ surfaces.

The XPS peak details of $C 1 \mathrm{~s}$ regions are reported in Fig. 2.

As to the bare samples (Fig. $2 \mathrm{a}^{\prime}-\mathrm{d}^{\prime}$ ), the $\mathrm{C} 1 \mathrm{~s}$ peak is a convolution of three main different components, corresponding respectively to: (i) $\mathrm{C}-\mathrm{C}$ and $\mathrm{C}-\mathrm{H}$ bonds $\left(\mathrm{C}_{1}\right.$ component, centered at binding energy, $\mathrm{BE}$, of $285.0 \mathrm{eV}$ ), (ii) $\mathrm{C}-\mathrm{O}$ bonds $\left(\mathrm{C}_{2}\right.$ component, centered at $\mathrm{BE}=286.5 \pm 0.2 \mathrm{eV}$ ) and (iii) carbon doubly bonded to oxygen species such as $\mathrm{C}(=\mathrm{O}) \mathrm{O}$ or $\mathrm{O}-\mathrm{C}-\mathrm{O}$ bonds $\left(\mathrm{C}_{3}\right.$ component, centered at $\mathrm{BE}=288.8 \pm 0.2 \mathrm{eV}$ ) [36].

It interesting to note that the $\mathrm{ZnO}-1$ surfaces exhibit a higher content of polar linkages than the $\mathrm{ZnO}-2$ and $\mathrm{ZnO}-3$ ones, as evidenced by the relative ratio of carbon-heteroatom bonds (i.e., $C_{2}+C_{3}$ components) with respect to the hydrocarbon species $\left(C_{1}\right.$ component). This predominance is likely responsible for the biodegradability of $\mathrm{ZnO}-1$ samples, i.e., the above-mentioned high reactivity towards surface dissolution processes prompted by the interaction with the protein.

After the protein immobilization, a broadening of $\mathrm{C} 1 \mathrm{~s}$ peak is observed for all the investigated samples (Fig. 2a-d); this effect has been taken into account by adding a new component in the peak fitting, i.e., the peptide bond $(-\mathrm{C}(=\mathrm{O})-\mathrm{NH})$-related peak $\left(\mathrm{C}_{4}\right.$, centered at $\mathrm{BE}$ of $\left.288.3 \pm 0.2 \mathrm{eV}\right)$.

Moreover, the comparison of spectra shows that the $C_{2} / C_{4}$ ratio is about 2 for $\mathrm{ZnO}-1, \mathrm{ZnO}-2$ and reference $\mathrm{Si}$ surfaces, while it is reduced to 1 for control $\mathrm{ZnO}-3$. This fact indicates that, notwithstanding the comparable protein mass uptake, the average orientation of $\mathrm{C}-\mathrm{O}, \mathrm{C}-\mathrm{N}, \mathrm{C}-\mathrm{S}$ bonds $\left(\mathrm{C}_{2}\right)$ with respect to $\mathrm{C}=\mathrm{O}$ species $\left(C_{4}\right)$ of the protein adlayers is different at the interface with the thin $\mathrm{ZnO}-\mathrm{SiO}_{2}$ and $\mathrm{Si}$ substrates with respect to the thick $\mathrm{ZnO}-3$ control film. This evidence suggests that $\mathrm{SiO}_{2}$-uncovered areas in both $\mathrm{ZnO}-1$ and $\mathrm{ZnO}-2$ thin films (see XPS discussion above) contribute significantly to the actual surface termination, thus consisting in hybrid $\mathrm{ZnO}-\mathrm{SiO}_{2}$ biointerface.

The evidence of hybrid $\mathrm{ZnO}-\mathrm{SiO}_{2}$ active surfaces for the newly deposited $\mathrm{ZnO}$ ultrathin layer is further supported by the $\mathrm{O} 1 \mathrm{~s}$ high-resolution spectra (not shown, see Fig. S1 in Supplementary material). Indeed, for the as-deposited $\mathrm{ZnO}$ films, the $\mathrm{O} 1 \mathrm{~s}$ photoelectron peak can be consistently decomposed into two components, respectively, at $530.5 \pm 0.2 \mathrm{eV}(\mathrm{OM})$ and $532.0 \pm 0.2 \mathrm{eV}(\mathrm{OH})$. The lower-binding-energy component is attributed to $\mathrm{O}^{2-}$ ions of the crystalline network, which is identified as originating from $\mathrm{O} 1 \mathrm{~s}$ core level of $\mathrm{Zn}-\mathrm{O}$ [37], while the higher-binding-energy component is usually attributed to $\mathrm{O}^{-}$species, i.e., the presence of loosely bound oxygen on the surface of $\mathrm{ZnO}$ film [38]. The surface-related component is prevailing in the ultrathin films $\mathrm{ZnO}-1$ and $\mathrm{ZnO}-2\left(\mathrm{OH} / \mathrm{O}_{\text {tot }}\right.$, respectively, of $66 \%$ and $63 \%$ ), while it is slightly lower than the OM component in $\mathrm{ZnO}-3$ film $\left(\mathrm{OH} / \mathrm{O}_{\text {tot }} \sim 45 \%\right)$. After the protein immobilization process, the OM component is hindered by the predominance of a new component centered at $\mathrm{BE}=531.5 \pm 0.2 \mathrm{eV}$, which is related to the protein $\mathrm{C}=\mathrm{O}$ bonds.

This protein-related component is comparably higher than the $\mathrm{OH}$ one for both the ultrathin $\mathrm{ZnO}-\mathrm{SiO}_{2}$ films (about 3:1), while it is the only one visible for the control $\mathrm{ZnO}-3$.

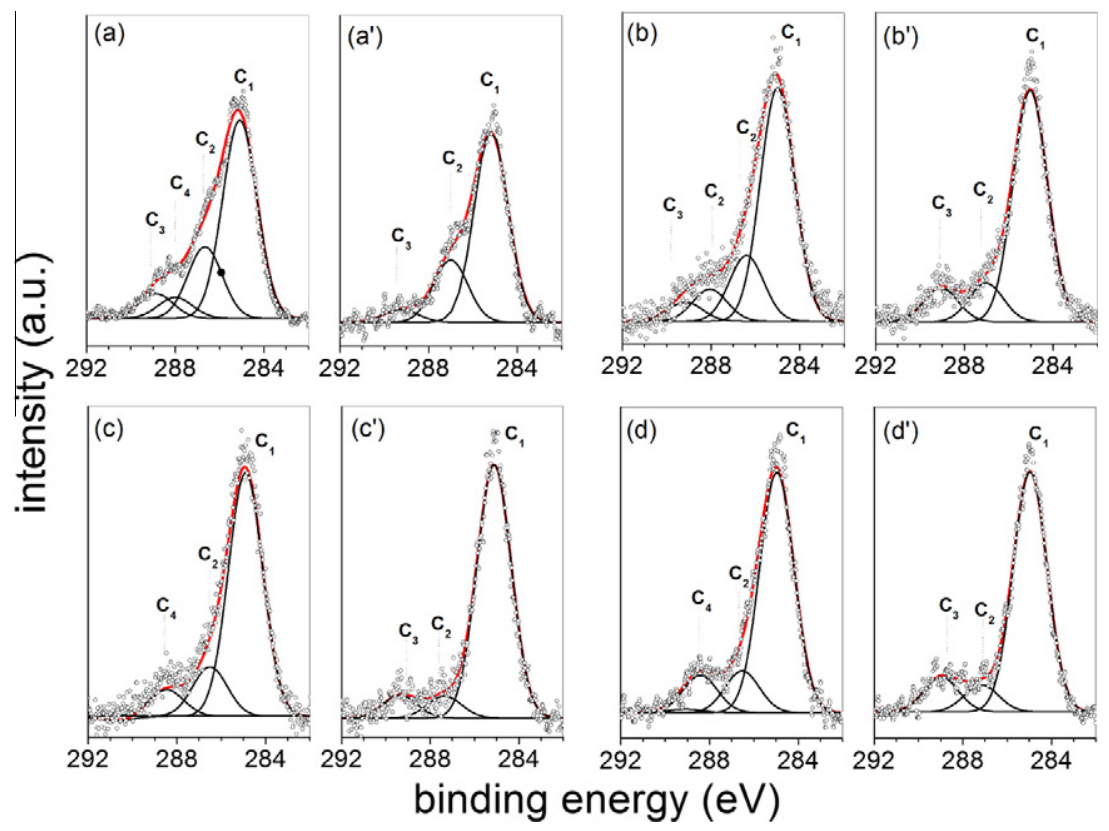

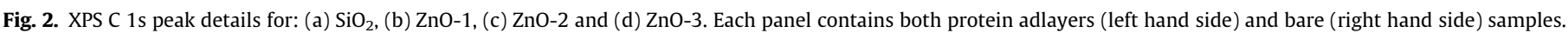


To summarize, evidence of comparable protein mass uptakes onto the different $\mathrm{ZnO}$-based films is provided by the attenuation of the substrate-related signals ( $\mathrm{Zn}, \mathrm{Si}$ and $\mathrm{OM}$ component of the oxygen peak) as well as the appearance of protein-related signals (nitrogen, C4 component of the carbon peak). The average protein orientation at the interface with the ultrathin $\mathrm{ZnO}$-based films seems to be affected by the hybrid $\mathrm{ZnO}-\mathrm{SiO}_{2}$ character of the surfaces with respect to the control $\mathrm{ZnO}-3$ sample.

Fluorescence microscopy was employed to scrutinize the response of the various $\mathrm{ZnO}$ deposited films to the binding of fluorescein-conjugated albumin as well as to implement data from XPS analysis about protein surface coverage, density and uniformity. Indeed, fluorescence analysis allowed determining in a semiquantitative way the protein uptake for the different $\mathrm{ZnO}$ films as well as the lateral mobility of the protein at the protein-zinc oxide interface.

Fig. 3 shows the representative LSM images recorded in fluorescence mode at the borderline between protein-exposed (brighter area) and masked (darker area) regions for control $\mathrm{SiO}_{2}$ (Fig. 3a), ultrathin $\mathrm{ZnO}-\mathrm{SiO}_{2}$ film ( $\mathrm{ZnO}-2$, Fig. 3b) and thick $\mathrm{ZnO}$ control (ZnO-3, Fig. 3c) samples.

As our experimental scheme involves nonspecific adsorption of the protein molecules onto substrates, the protein molecules were randomly distributed over the entire protein-exposed surface area. Indeed, an enhanced fluorescence, related to the enhancement of emission recorded at $519 \mathrm{~nm}$ of wavelength, is observed for all the $\mathrm{ZnO}$ films as well as the control glass $\left(\mathrm{SiO}_{2}\right)$ upon the uptake of fluorescein-labeled protein. By assuming that the uniformity of the antigen coverage can be correlated with the standard deviation in pixel luminance for each of the samples, it appears that the protein coverage is less homogeneous on the ultrathin $\mathrm{ZnO}-\mathrm{SiO}_{2}$ films than on the thick $\mathrm{ZnO}$ sample.

What is more, the comparison of the fluorescence intensity for the differently protein-exposed films normalized vs. the corresponding control bare substrate and subtracted of the background emission (Fig. 3d) evidences roughly a twofold increase in average fluorescent intensity $(p<0.001)$ of the $\mathrm{ZnO}$-based samples compared with $\mathrm{SiO}_{2}$, notwithstanding the comparable amount of immobilized protein (as estimated by XPS). This fact points to the capability of our deposited ultrathin $\mathrm{ZnO}$ films to work as nanoplatform for fluorescence enhancement upon interaction with the protein.

The laterally homogeneous and ultrathin $\mathrm{ZnO}$-based films have been compared with $\mathrm{ZnO}-\mathrm{SiO}_{2}$ nanoplatforms in order to scrutinize the lateral diffusion properties of protein adlayers on the patterned micropore arrays vs. the unpatterned $\mathrm{ZnO}$ films.

As matter of fact, the reduced critical dimensionality of $\mathrm{ZnO}$ materials at the nanoscale, either by topographic or by chemical structuring, such as $\mathrm{ZnO}$ nanorods or SAM-modified planar $\mathrm{ZnO}$, is known to play a fundamental role in the fluorescence enhancement effect [1]. Therefore, the dimensional control of $\mathrm{ZnO}$ nanomaterials is very critical to trigger fluorescence detection from proteins. In this context, we have previously shown that ZnO nanoplatforms, consisting in thin films of hexagonally patterned $\mathrm{ZnO}$ nanoring arrays and $\mathrm{SiO}_{2}$ circular areas, as obtained by colloidal template-assisted MOCVD process, are effective for immobilization of albumin [21]. As the effective process integration of colloidal lithography with MOCVD performed at extremely mild conditions has been demonstrated at the temperature/times of deposition as those used in the case of ZnO-2 samples [4,20], the ultrathin $\mathrm{ZnO}-2$ films have been patterned into dense and regular micropore arrays (ZnO-2 NP samples).

The mobility properties of the protein molecules adsorbed on the two types of $\mathrm{ZnO}$ substrates have been assessed by FRAP experiments, which consist in using a focused laser beam at high power to intentionally photobleach quickly and locally fluorescently tagged proteins. Mobile proteins can exchange with their unbleached counterparts, leading to the recovery of fluorescence in the photobleached area at rates proportional to protein mobility.

FRAP is commonly employed to measure long-time two-dimensional diffusion of proteins adsorbed at solid-liquid interfaces, which depends on both protein-surface and protein-protein interactions $[39,40]$.

Fig. 4 shows the results of the FRAP experiment performed on the protein adlayer onto both unpatterned (Fig. 4a) and patterned (Fig. 4b) $\mathrm{ZnO}-2$ samples.
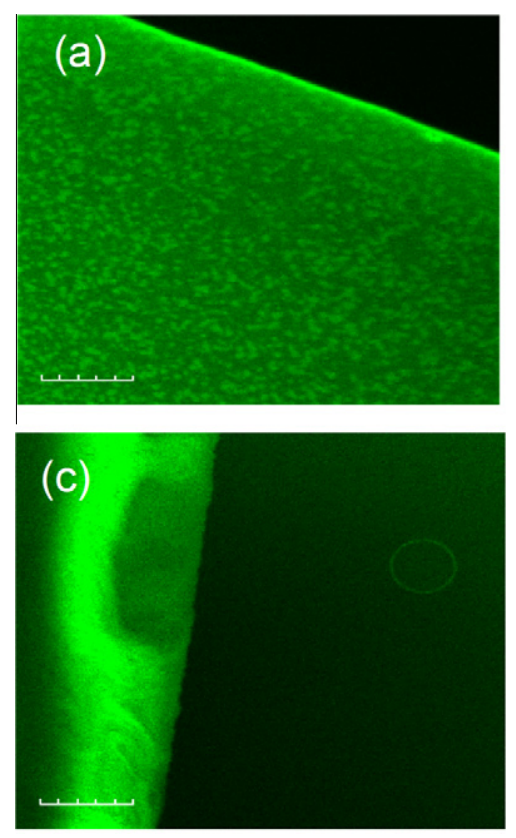
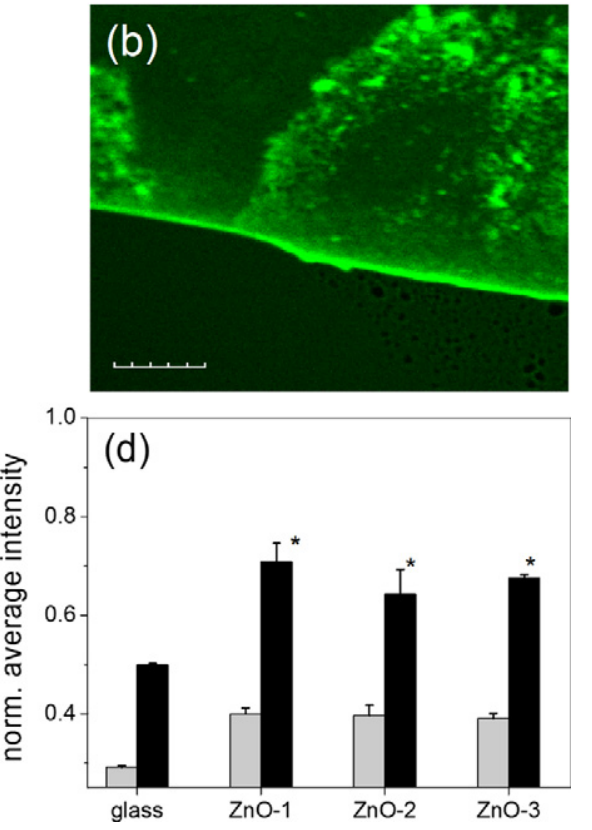

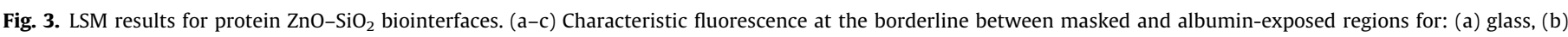

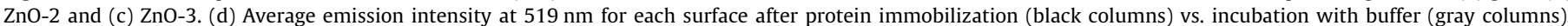

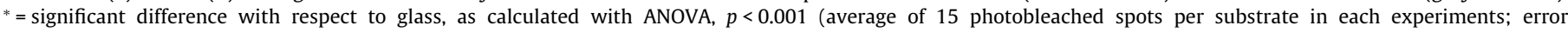
bars = standard deviation). (For interpretation of the references to colour in this figure legend, the reader is referred to the web version of this article.) 


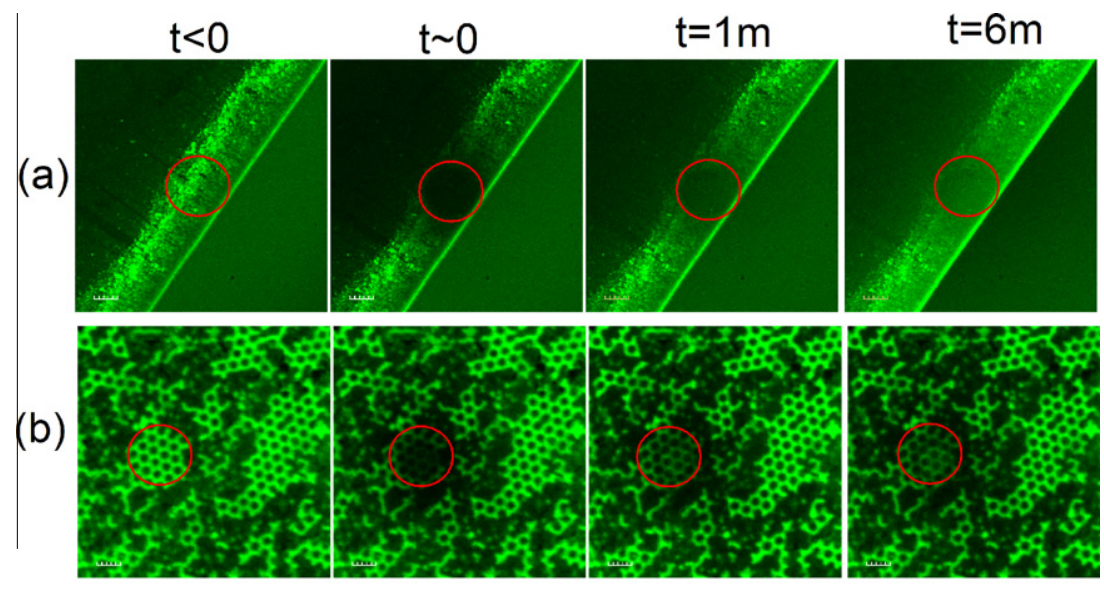

(c)

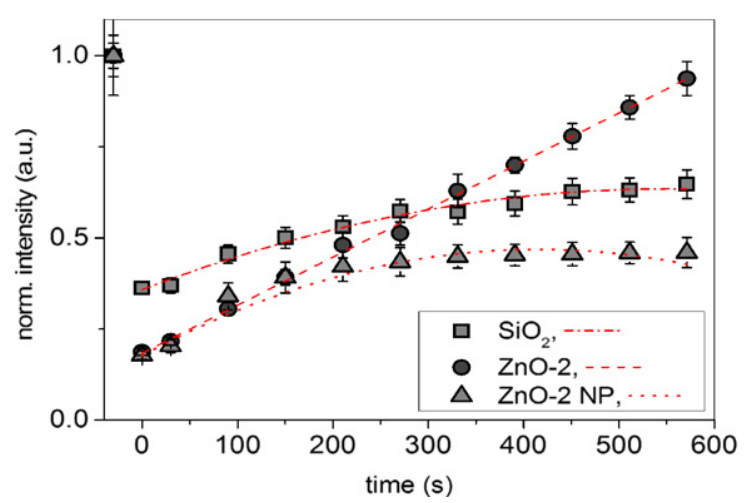

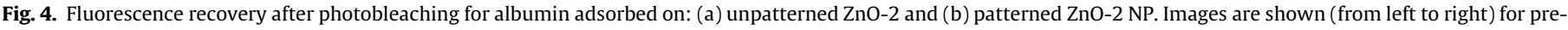

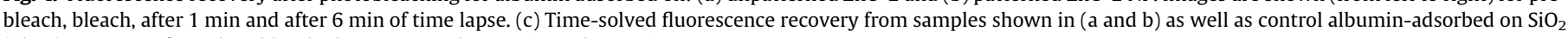
(glass). Average of 12 photobleached spots per substrate in each experiment.

It is worth of note that both types of protein-ZnO biointerfaces exhibit an extremely dynamic character, as well addressed by the micrographs taken at $t \sim 0$. In fact, the initial fluorescence before bleaching $(t<0)$ is expected to be quenched in a well-defined circular area by the high-intensity laser beam (circles drawn in Fig. 4a and $\mathrm{b}, t<0$ ). However, due to very fast random motion/diffusion of bleached protein molecules exchanging their position in the bleached area with non-bleached molecules from the surrounding, the bleached circles are not well defined already within the time required to record the first micrograph $(t \sim 0)$. This finding suggests that the albumin aggregates on the $\mathrm{ZnO}$ substrates have a relatively fast diffusion at the surfaces and move around independently.

As to the fluorescence recovery $(t>0)$, two different kinetics are observed for the unpatterned and micropore-patterned $\mathrm{ZnO}$-based films, corresponding to linear and polynomial fits, respectively (Fig. 4c). In particular, the protein molecules adsorbed on the ZnO-2 NP exhibit only a partial recovery and a lower effective diffusion than those adsorbed on the $\mathrm{ZnO}-2$ surfaces. It is noteworthy that the fluorescence recovery from the protein adlayer on the reference glass substrate exhibits a polynomial curve trend similar to that observed for the hybrid $\mathrm{ZnO}-\mathrm{SiO}_{2}$ micropore sample. The diffusion coefficients calculated by using the Axelrod's algorithm [41] are, respectively, of $2.4 \times 10^{-10} \mathrm{~cm}^{2} / \mathrm{s}$ on glass, $1.5 \times 10^{-10} \mathrm{~cm}^{2} / \mathrm{s}$ on $\mathrm{ZnO}-2$ and $1.0 \times 10^{-11} \mathrm{~cm}^{2} / \mathrm{s}$ on $\mathrm{ZnO}-2 \mathrm{NP}$. These findings indicate that, apart from the obvious enhanced friction suffered by the molecules moving inside the pore rims of the patterned $\mathrm{ZnO}-2$ film in comparison with the unpatterned sample (i.e., topographic effect), the presence of $\mathrm{SiO}_{2}$ areas confined by the $\mathrm{ZnO}$ is relevant to trigger the protein mobility at the biointerface (i.e., chemical effect). Similar results, pointing to a friction-reduced lateral diffusion on pore rims compared with that of the area within the pore, have been reported for lipid membranes on ordered porous silicon sub- strates [42]. In our case, the protein diffusion rate on the hybrid $\mathrm{ZnO}-\mathrm{SiO}_{2}$ surface is likely be affected not only by the topography by also by the surface chemistry and charge. In fact, the latter are crucial factors for the strength of interaction and the protein conformation at the protein-solid interface, thus affecting the transport process elucidated by FRAP $[40,43,44]$.

It must be also mentioned that, since the $\mathrm{ZnO}$ isoelectric point is higher than that of $\mathrm{SiO}_{2}$ (i.e., IEP $\sim 9.5$ vs. $\sim 2$ [45]), it is consistent that the fraction of immobile and laterally diffusing molecules at the solid-liquid interface is locally different on the hybrid $\mathrm{ZnO}-$ $\mathrm{SiO}_{2}$ system.

FRAP experiments are currently underway to address more in detail the potential influence of 3D diffusion on the apparent 2D diffusion measured by FRAP in the protein adsorption process. Further studies with a wide range of new patterns, for instance by changing the density and/or the area of the $\mathrm{ZnO}-\mathrm{SiO}_{2}$ pore arrays, will allow the tuning of the surface reactivity towards transport processes at the biointerface to be used as models in biological studies or in applications such as biosensors.

\section{Conclusions}

This study is offered as an initial investigation for the preparation of $\mathrm{ZnO}$-based sensors, by elucidating on an integrated MOCVD-CL deposition strategy to produce hybrid $\mathrm{ZnO}_{-} \mathrm{SiO}_{2}$ platforms having tunable chemistry and topography, which in turn enable different fluorescence detections during biomolecule binding events. Experiments are currently underway to address this problem in more detail, in particular the determination of transport properties as function of the $\mathrm{ZnO}$ pattern, protein concentration, reversibility and reusability issues. 


\section{Acknowledgment}

Authors would like to acknowledge INSTM for the support provided to the present research.

\section{Appendix A. Supplementary material}

Supplementary data associated with this article can be found, in the online version, at doi:10.1016/j.jcis.2011.09.014.

\section{References}

[1] A. Dorfman, N. Kumar, J.I. Hahm, Adv. Mater. 18 (2006) 2685.

[2] L. Wang, Y. Sun, J. Wang, J. Wang, A. Yu, H. Zhang, D. Song, J. Colloid Interface Sci. 351 (2010) 392.

[3] Z.L. Wang, Mater. Sci. Eng. R - Rep. 64 (2009) 33.

[4] M.E. Fragalà, C. Satriano, G. Malandrino, Chem. Commun. 7 (2009) 839.

[5] A. Dorfman, N. Kumar, J.I. Hahm, Langmuir 22 (2006) 4890.

[6] S.C. Lyu, Y. Zhang, C.J. Lee, H. Ruh, H.J. Lee, Chem. Mater. 15 (2003) 3294.

[7] X. Ren, D. Chen, X. Meng, F. Tang, X. Hou, D. Han, L. Zhang, J. Colloid Interface Sci. 334 (2009) 183.

[8] Z. Li, R. Yang, M. Yu, F. Bai, C. Li, Z.L. Wang, J. Phys. Chem. C 112 (2008) 20114.

[9] J. Zhou, N. Xu, Z.L. Wang, Adv. Mater. 18 (2006) 2432.

[10] B. Fang, C. Zhang, G. wang, M. Wang, Y. Ji, Sens. Actuators, B 155 (2011) 304.

[11] A. Umar, M.M. Rahman, A.A. Hajry, H.-B. Hahn, Talanta 78 (2009) 284.

[12] N. Kumar, A. Dorfman, J.-I. Hahm, Nanotechnology 17 (2006) 2875.

[13] F. Zhang, X. Wang, S. Ai, Z. Sun, Q. Wan, Z. Zhu, Y. Xian, L. Jin, K. Yamamoto, Anal. Chim. Acta 519 (2004) 155.

[14] V. Adalsteinsson, O. Parajuli, S. Kepics, A. Gupta, W.B. Reeves, J.-I. Hahm, Anal. Chem. 80 (2008) 6594.

[15] M.E. Fragalà, C. Satriano, J. Nanosci. Nanotechnol. 10 (2010) 5889.

[16] S. Krishnamoorthy, T. Bei, E. Zoumakis, G.P. Chrousos, A.A. Iliadis, Biosens. Bioelectron. 22 (2006) 707.

[17] V. Adalsteinsson, O. Parajuli, S. Kepics, A. Gupta, W.B. Reeves, J.-I. Hahm, Anal. Chem. 80 (2008) 6594.

[18] M.E. Fragala, Y. Aleeva, C. Satriano, J. Nanosci. Nanotechnol. 11 (2011), doi:10.1166/jnn.20115083.

[19] H.Y. Park, H.Y. Go, S. Kalme, R.S. Mane, S.-H. Han, M.-Y. Yoon, Anal. Chem. 81 (2009) 4280.
[20] M.E. Fragalà, C. Satriano, Y. Aleeva, G. Malandrino, Thin Solid Films 518 (2010) 4484.

[21] M.E. Fragalà, C. Satriano, J. Nananosci. Nanotechnol. 10 (2010) 5889.

[22] F.A. Denis, P. Hanarp, D.S. Sutherland, Y.F. Dufrene, Langmuir 20 (2004) 9335

[23] A. Ruiz, A. Valsesia, F. Bretagnol, P. Colpo, F. Rossi, Nanotechnology 18 (2007) 505306.

[24] B.R. Pistillo, R. Gristina, E. Sardella, S. Lovascio, P. Favia, M. Nardulli, R d'Agostino, Plasma Process. Polym. 6 (2009) S61.

[25] G.M.L. Messina, C. Satriano, G. Marletta, Chem. Commun. (2008) 5031

[26] P. Hanarp, D.S. Sutherland, J. Gold, B. Kasemo, Nanostruct. Mater. 12 (1999) 429.

[27] G. Singh, V. Gohri, S. Pillai, A. Arpanaei, M. Foss, Peter Kingshott, ACS Nano 5 (2011) 3542.

[28] M.E. Fragalà, Y. Aleeva, G. Malandrino, Thin Solid Films 519 (2010) 7694.

[29] G. Malandrino, M. Blandino, M.E. Fragalà, M. Losurdo, G. Bruno, J. Phys. Chem. C 112 (2008) 9595.

[30] A.I. Martin-Conception, F. Yubero, J.P. Espinos, J. Garcia-Lopez, S. Tougaard, Surf. Interface Anal. 35 (2003) 984.

[31] G.M.L. Messina, C. Satriano, G. Marletta, Colloids Surf. B 70 (2009) 76

[32] H.F.A. Trimbos, H.N. Stein, J. Colloid Interface Sci. 77 (1980) 386.

[33] I. Lynch, K.A. Dawson, Nanotoday 3 (2008) 40.

[34] T. Xia, M. Kovochich, M. Liong, L. Madler, B. Gilbert, H.B. Shi, J.I. Yeh, J.I. Zink, A.E. Nel, ACS Nano 2 (2008) 2121.

[35] A.E. Nel, L. Mädler, D. Velegol, T. Xia, E.M.V. Hoek, P. Somasundaran, F. Klaessig V. Castranova, M. Thompson, Nat. Mater. 8 (2009) 543.

[36] K.G. Saw, K. Ibrahim, Y.T. Lim, M.K. Chai, Thin Solid Films 515 (2007) 2879.

[37] J.-C. Dupin, D. Gonbeau, P. Vinatier, A. Levasseur, Phys. Chem. Chem. Phys. 2 (2000) 1319.

[38] K. Kotsis, V. Staemmler, Phys. Chem. Chem. Phys. 8 (2006) 1490

[39] R.D. Tilton, A.P. Gast, C.R. Robertson, Biophys. J. 68 (1990) 1321.

[40] E.P. Vieira, S. Rocha, M.C. Pereira, H. Möhwald, M.A.N. Coelho, Langmuir 25 (2009) 9879.

[41] D. Axelrod, D.E. Koppel, J. Schlessinger, E. Elson, W.W. Webb, Biophys. J. 16 (1976) 1055.

[42] D. Weiskopf, E.K. Schmitt, M.H. Klühr, S.K. Dertinger, C. Steinem, Langmuir 23 (2007) 9134

[43] W. Norde, Macromol. Symp. 103 (1996) 5.

[44] C.K. Choi, J.D. Fowlkes, S.T. Retterer, P. Siuti, S. Iyer, M.J. Doktycz, ACS Nano 4 (2010) 3345.

[45] G.A. Parks, Chem. Rev. 65 (1965) 177. 